\title{
The influence of magnetic field and cathode dimensions on plasma
}

\section{characteristics in hollow cathode system}

\section{Baraa Afif and Qusay Adnan Abbas}

Department of Physics, College of Science, University of Baghdad, Baghdad, Iraq

E-mail: qusayiraqi@yahoo.com

\begin{abstract}
Experimental study on the effect of cylindrical hollow cathode, working pressure and magnetic field on spatial glow distribution and the characteristics of plasma produced by dc discharge in Argon gas, were investigated by image analyses for the plume within the plasma. It was found that the emission intensity appears as a periodic structure with many peaks appeared between the electrodes. Increasing the pressure leads to increase the number of intensity peaks finally converted to continuous form at high pressure, especially with applied of magnetic field, i.e. the plasma is more stable with the presence of magnetic field. The emission intensity study of plasma showed that the intensity has a maximum value at 1.07 mbar pressure and decrease with more pressure.
\end{abstract}

Key words

Hollow cathode, dc

discharge, Glow

discharge region,

magnetic field.

Article info.

Received: Jan. 2018

Accepted: Mar. 2018

Published: Sep. 2018

$$
\begin{aligned}
& \text { تأثير المجال المغناطيسي وأبعاد الكاثود على خصائص البلازما في منظومة الكاثود المجوف } \\
& \text { براء عفيف مسلم و قصي عدنان عباس }
\end{aligned}
$$

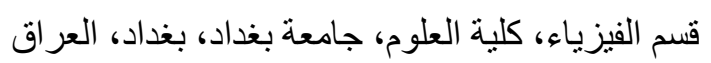

الخلاصة

أجريت دراسة تجريبية حول تأثير الكاثود الأسطواني المجوف، ضغط التئ العمل ووجود المجال المغناطيسي،

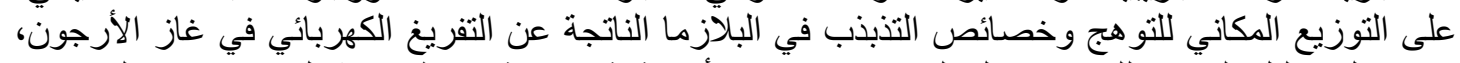

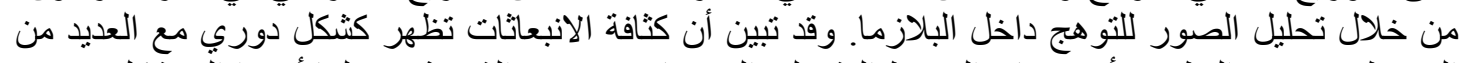

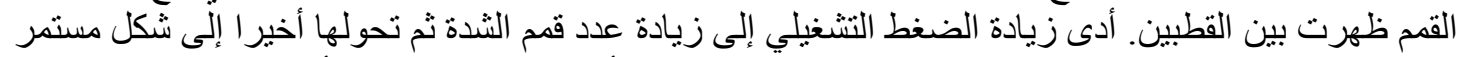

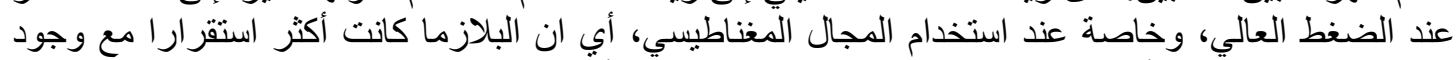

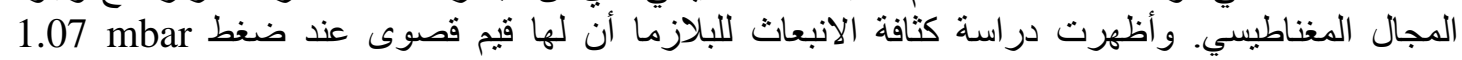
وتنخفض مع مزيد من الضغط.

\section{Introduction}

Various structures appear in the glowing column, produced by $\mathrm{dc}$ discharge, depending on the gas pressure. The phenomena within the tube can be separated into two distinct groups: The cathode glow, the negative glow, and the Crookes and Faraday dark spaces belong to the cathode. They are affected strongly by pressure but do not depend markedly on tube length. The positive column, also known as the 'plasma', is elongated by increasing the length of the tube. It becomes striated because electrons are absorbed in the process of ionizing and otherwise imparting energy to the gas molecules, and newly produced secondary electrons require acceleration before they can cause ionization in their turn. The interval between striations depends on the pressure, and the visible effect is often indistinct. Striations tend to be more obvious in polyatomic gases $\left(\mathrm{O}_{2}, \mathrm{~N}_{2}\right.$, 
$\mathrm{H}_{2} \mathrm{O}$, etc.) than in monatomic gases such as Ar [1].

The hollow cathode (HCD) was first described by Paschen in 1916. Since then, its fundamental characteristics have been studied extensively [2]. The hollow cathode discharge (HCD), a specialized type of glow discharge, has been the subject of investigations by physicists (in particular) and chemists for over a half century. Hollow cathode discharges are capable of generating dense plasmas and have been used for development of high-rate, low-pressure, highefficiency processing machines. The geometric feature of a HCD promotes oscillations of hot electrons inside the cathode, thereby enhancing ionization, ion bombardment of inner walls and other subsequent processes. At the same power the hollow cathode exhibits plasma density one to two orders of magnitude higher than that of conventional planar electrodes [3].

In a hollow cathode configuration, the sputtering and the discharge plasma are concentrated into a hollow cathode cavity (conditions are about 0.1-10 mbar pressure, 200-500 V and 10-100 $\mathrm{mA}$ ), which consequences more effective ionization in the negative glow. Therefore, hollow cathode discharges can yield more ions than other types of sources and could benefit from reconsideration as an ion source. However, the intense plasma conditions that can be generated in a hollow cathode motivate for further investigations. Where in very high current densities can be derived at minimal discharge voltages, an effective analytic excitation environment than the more open planar geometry, a hollow cathode discharge is infrequently used as ion source [4].

In recent years hollow-cathode discharges in the E/n-range above $500 \mathrm{Td}(\mathrm{E}$ is the electric field strength and $\mathrm{n}$ the gas number density) have gained rising attention in many fields of research. They have been used as sources of high intensity electronbeams, which can carry currents of several kA's, as well as transmitters of $\mathrm{X}$-rays, covering a wide spectrum, and as ion-beam sources [5]. Several hundred literature reports may be found concerning various aspects of the HCD. Despite this, many analytical chemists today would consider the HCD as merely a sharp line source for atomic absorption spectrometry. While this is certainly its most important present application, the HCD has a long history as a spectrochemical emission source allowing direct excitation and analysis of samples [6].

\section{Experimental set up}

Fig. 1 schematics the hollow cathode electrodes (made of Aluminum) that were designed to be used in the dc discharge system. The cathodes have cylindrical external shape with outer diameter of $22 \mathrm{~mm}$ and a length of $45 \mathrm{~mm}$ whiles the inner diameter $10 \mathrm{~mm}$ and a depth of $19 \mathrm{~mm}$. On the other hand, the Anode electrode (made from Aluminum) has disk shape with thickness $2 \mathrm{~cm}$ and diameter of $10 \mathrm{~mm}$. The inter- electrodes separation between the electrodes is $5.5 \mathrm{~cm}$. 


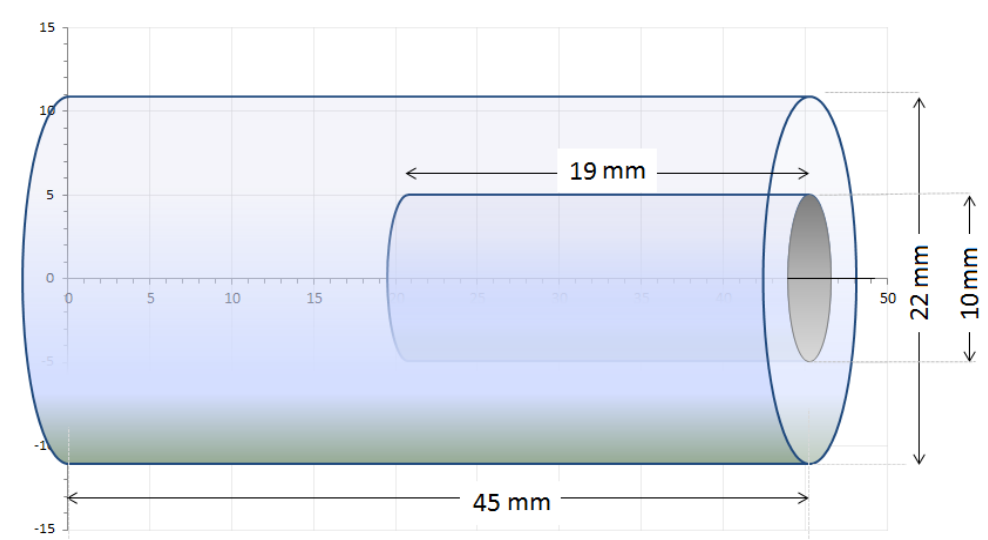

Fig. 1: Schematic of hollow cathode electrode used in the dc discharge system.

The vacuum chamber of the system (as shown in Fig. 2) was made of cylindrical stainless steel tube. The two ends of chamber were closed by Pyrex windows, by two stainless steel flanges, and with small quartz window fixed in its center that allows seeing the generated plasma. Two smaller pipe connected in mid of the chamber, one of it was connected to pumping systems, while the other was used to deliver the Argon gas. The cylindrical electrodes (hollow cathode and anode electrodes) were made from Aluminum. Both electrodes are fixed by Teflon to prevent any connection with the chamber walls.

The chamber was evacuated by two stages rotary pump, CIT-ALCATEL Annacy, (made in France) to a base pressure $1 \times 10^{-2}$ mbar. Pirani gauge type Edward (made in England) was used to measure the pressure of the chamber from atmospheric to the base pressure of the vacuum system. $4 \mathrm{kV} \mathrm{dc}$ voltage was applied on the electrodes to generate the discharge in argon gas between two electrodes. Small permanent magnet, with disc shape, was put behind the hollow cathode electrode to confine the plasma. The maximum value of the magnetic field from the permanent magnet is $30 \mathrm{G}$. The magnetic field strength distribution (B) was measured using Tesla meter model (magnetfeldmeßgerat) from Phywe company (made in Germany). The plasma characteristics were investigated by using emission spectroscopy type (Thorlabs Compact CCD 100 M Spectrometers) for wavelength range from $320 \mathrm{~nm}$ to $740 \mathrm{~nm}$.

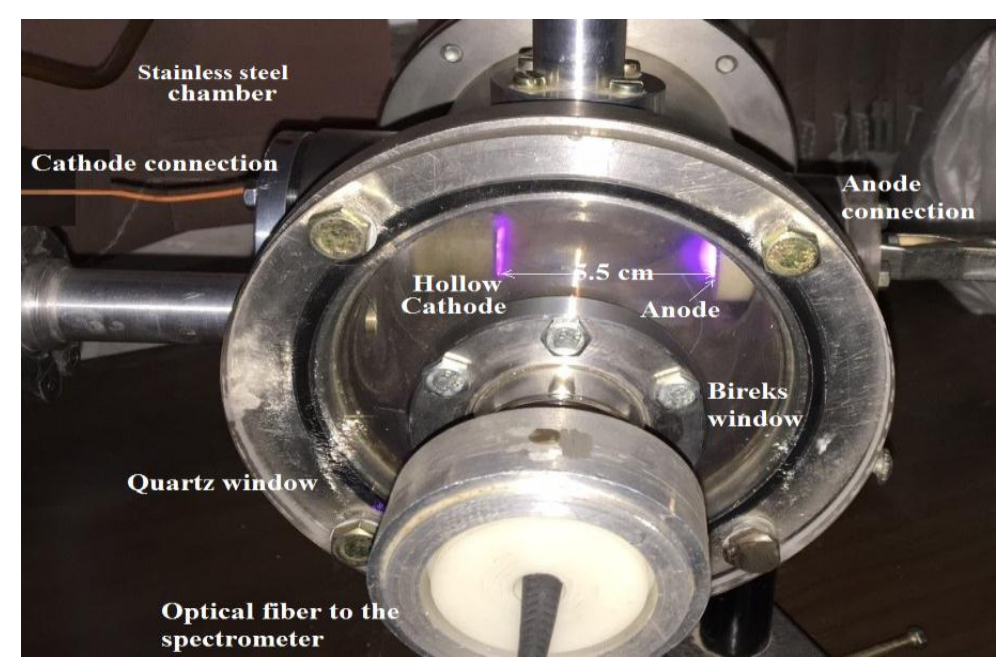

Fig. 2: The chamber of hollow cathode system. 


\section{Results and discussion}

Fig. 3 schematic the effect of increasing of argon pressure on the glow discharge regions for Argon gas between two electrodes in hollow cathode system, using direct applied voltage about $4 \mathrm{kV}$ at different working pressures $(0.27,0.53,0.67,0.80,1.07$ and 1.33 mbar) without magnetic field. It is pointed out from this figure that when the pressure increases the cathode regions (cathode fall) are compressed, the negative glow becomes a thin layer of intense luminosity, while the positive column and anode fall increase. This change in the glow discharge structure with increasing of the pressure can be described as: since the mean free path of electrons is inversely proportional to the gas pressure, it follows that the distance required for an electron to travel before it has produced adequate ionization to sustain the glow would also be inversely proportional to the pressure. Then, the thickness of the cathode dark region decreases as the pressure is increases (i.e. the cathode fall is compressed). Consequently, the negative glow region becomes a thin layer of intense luminosity and the positive column region and anode fall increase.
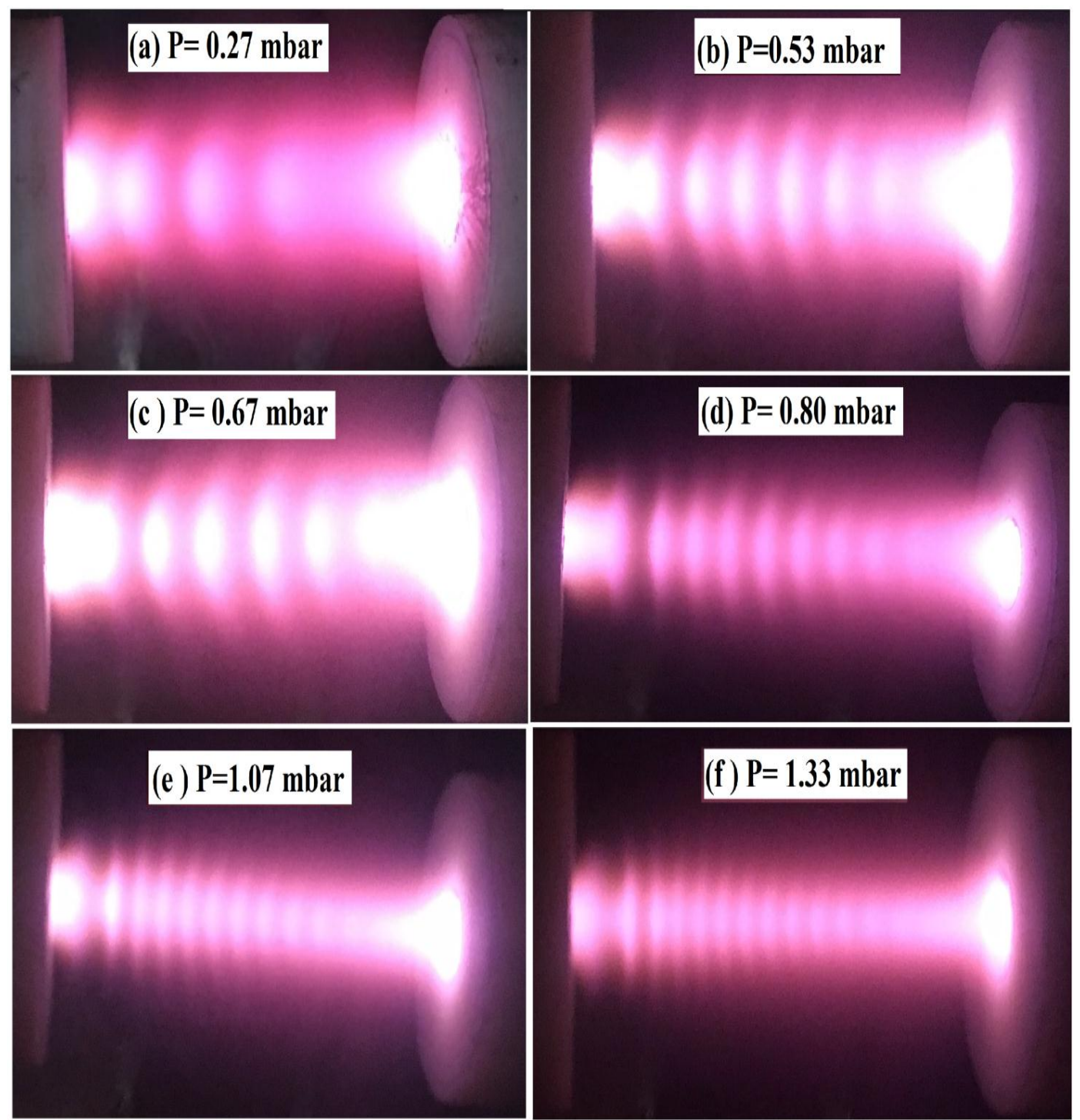

Fig. 3: Effect of Ar gas pressure on the glow discharge structure of the hollow cathode system without magnetic field. 
On the other hand, the presence of electric and magnetic fields together in the magnetron trap the electrons close to the surface of the hollow cathode (in the region of strong electric field). Electrons follow helical paths around the magnetic field lines so undergoing more ionizing collisions with gaseous neutral near the hollow cathode. It also means that the plasma can be sustained at a lower pressure. Fig. 4 estimated the effect of a magnetic field strength on the dc. glow discharge regions of hollow cathode system at a different pressure. The results indicated the present of magnetic field causes the cathode regions (cathode fall) are compressed, negative glow becomes a thin layer of intense luminosity, as well as the anode fall and the positive column increases. This compression in cathode fall can be explained as follows: the transverse direction of the magnetic field will bend the paths of most electrons that have relatively high speed, normal to cathode surface and enable them to produce the necessary ionization to maintain the discharge while moving a shorter distance along the axis in the cathode dark region. Thus, the length of the cathode dark region is reduced. While the increasing of the positive column length was caused by the transverse magnetic field will constrain the diffusion of charged particles perpendicular to its direction.
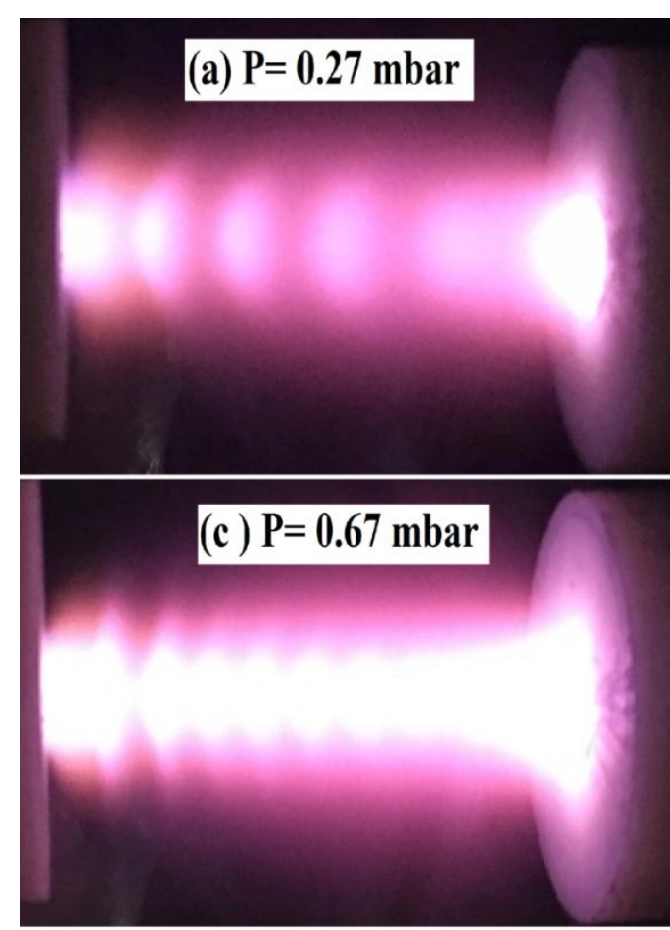

(e ) $\mathrm{P}=1.07 \mathrm{mbar}$

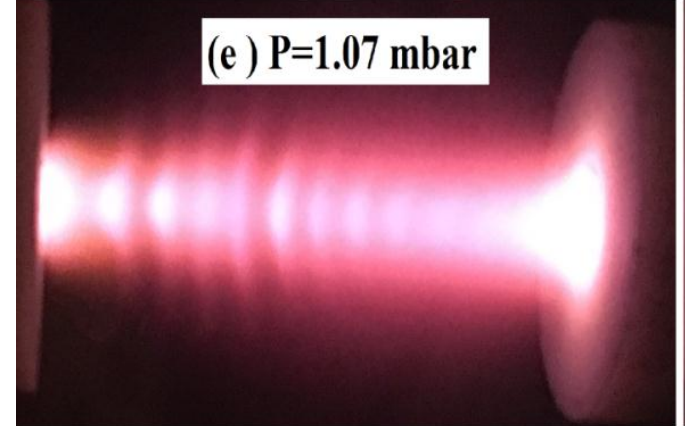

Fig. 4: Influence of Ar gas pressure on the glow discharge region in the hollow cathode system in the present of magnetic field.
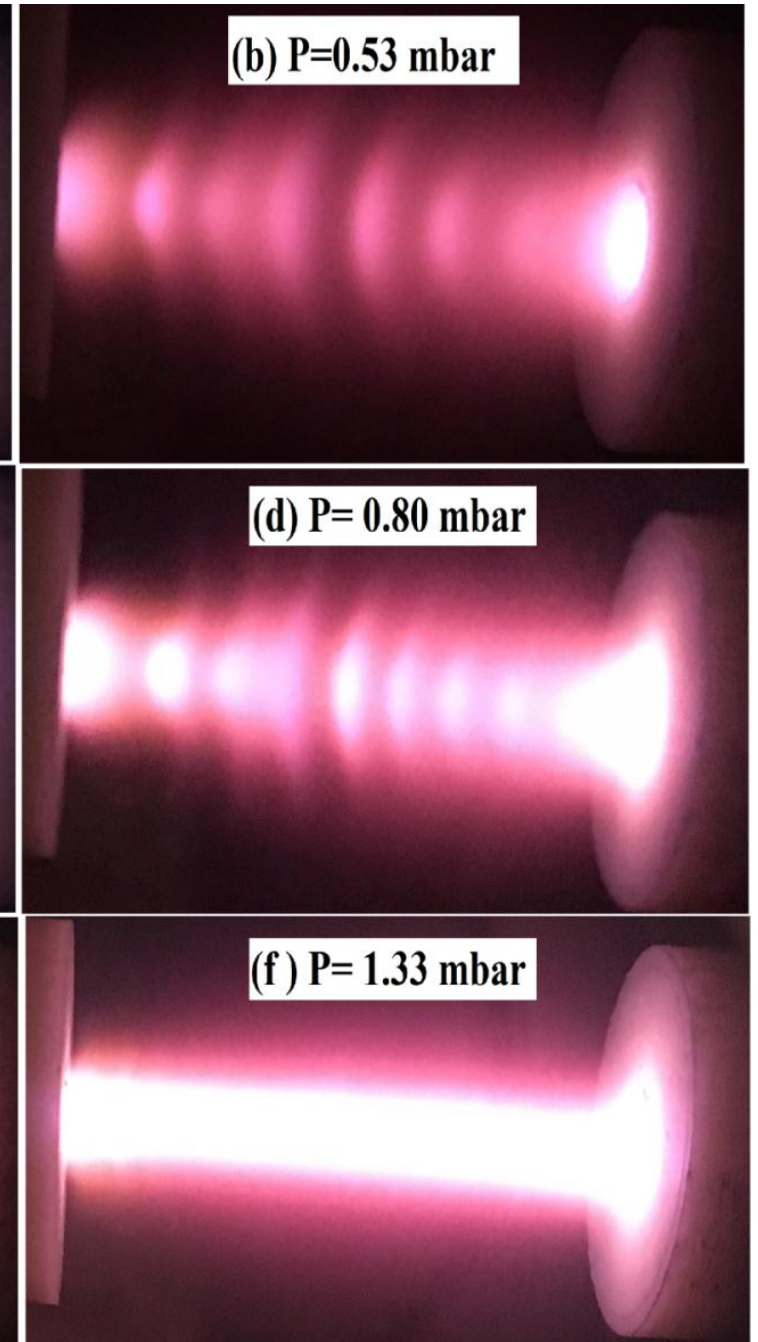
The emission intensity of discharge regions in this system are analyzed using the image $\mathbf{J}$ software and converted to $3 \mathrm{D}$ forms where the third dimension represents the amount of brightness in the image. These shapes were used later to find the intensity behavior on the central line. Fig. 5 shows the 3D image for the spatial emission intensity distribution by image analysis of Fig. 2 for the discharge glow of cylindrical hollow cathode system at different working pressure $(0.27,0.53,0.67,0.80,1.07$ and 1.33 mbar). Many features can be observed from Fig. 5, the maximum intensity occur in the region near from the cathode surface (where the electric field is strong in this region). The plasma discharge regions are compression with increasing of gas pressure. The number of discharge regions that appear increasing with increasing of gas pressure. The glow discharge intensity in the region between two electrodes is nonhomogeneous which increasing in the region nears the surface of two electrodes.

From 3D glow representation the glow distribution profile on central line were deduced using the image $\mathbf{J}$ software for the three cathodes design in two cases (with and without magnetic field) at different working pressure, to make a comparison between the different working conditions, where the most variance appeared on the line of symmetry (between electrode centers).

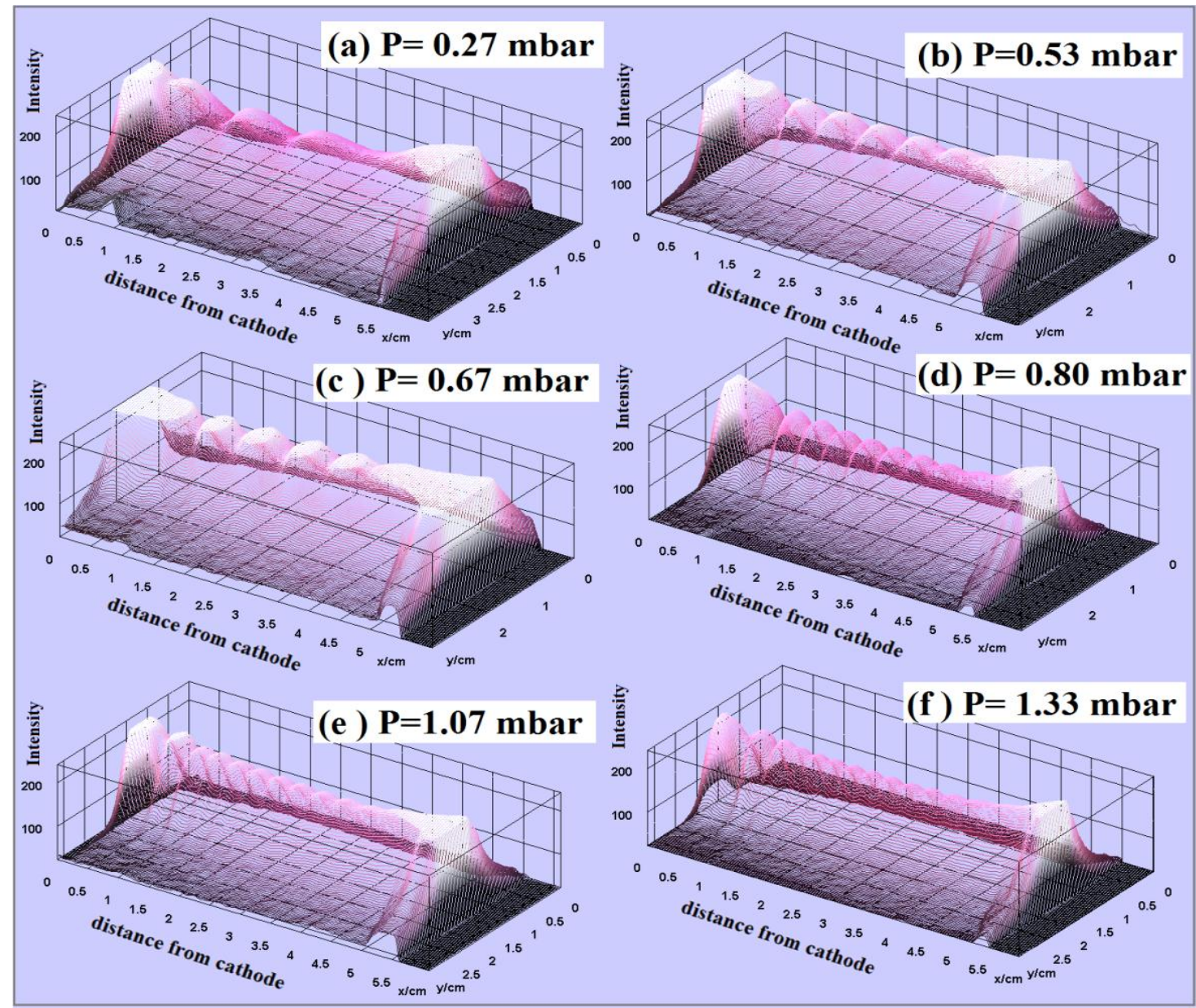

Fig. 5: Three dimensional glow distribution using the hollow cathode system at different working pressure, without magnetic field. 
Figs. 6 and 7 show the variation in intensity distribution between two electrodes of hollow cathode system with increasing of gas pressure in the absence and presence of magnetic field, respectively. One can observe from Fig. 6 that the emission intensity increasing with decreasing of gas pressure. This behavior can be explained as, the increasing of gas pressure causes to increasing of inelastic collision of electron with $\mathrm{Ar}$ atoms. Thus, the increasing of gas pressure shown decreasing of electron temperature and this causes to decrease the light emission intensity with increasing of gas pressure. This result agreement with those observed by references [7, 8]. On the other hand, the results of Fig. 7 showed that, in the presence of magnetic field, the emission intensity shown inverse behavior to that in the absence of magnetic field (i.e. the emission intensity increasing with increasing of gas pressure). This behavior may be explained as, the presence of magnetic field causes to increase the plasma confinement and this will increase the electron inelastic collision with argon atoms and causes to decrease the electron temperature. This is due to the characteristics of hollow cathode at the low pressures to produce more energetic excitation [9].

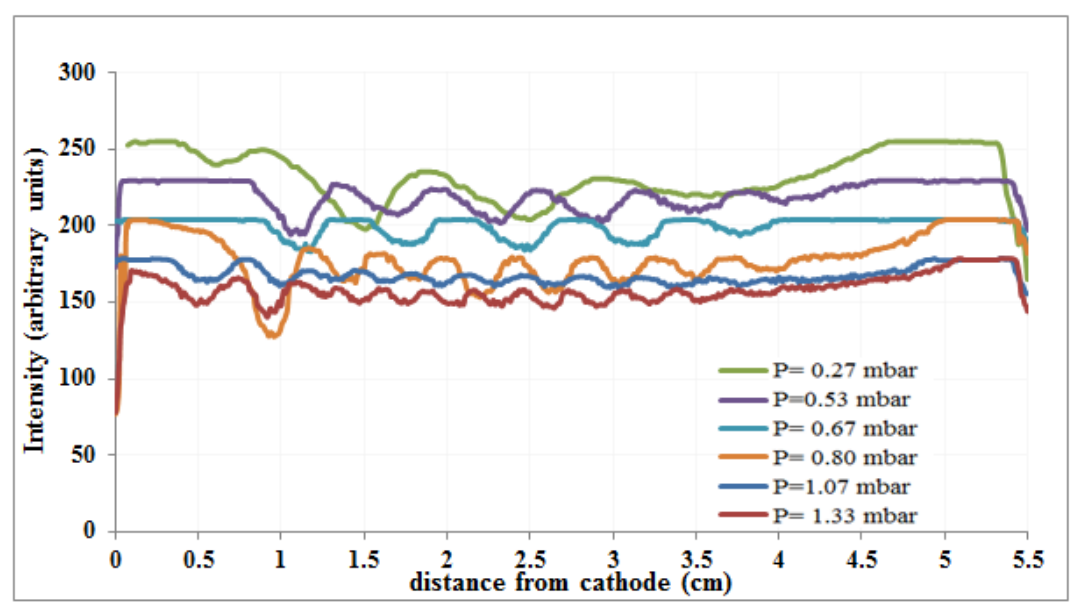

Fig. 6: Glow distribution on central line using the hollow cathode system at different working pressure, without magnetic field.

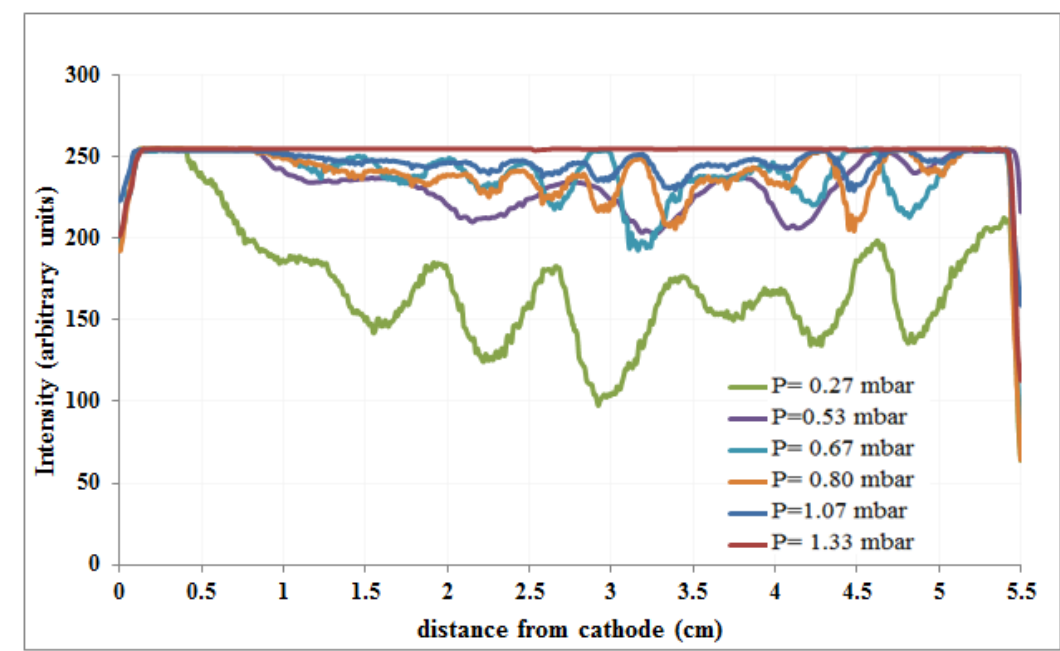

Fig. 7: Glow distribution on central line using the hollow cathode system at different working pressure, with magnetic field. 
Fig. 8 shows the influence of magnetic field on glow distribution between two electrodes at constant pressure 0.27 mbar. This selection of this pressure because the change is obvious. The results illustrate the emission light intensity reduced in the presence of magnetic field. The glow discharge regions shifted from its original positions. These behaviors may be due to the mean free path of electrons was reduced in the presence of magnetic field.

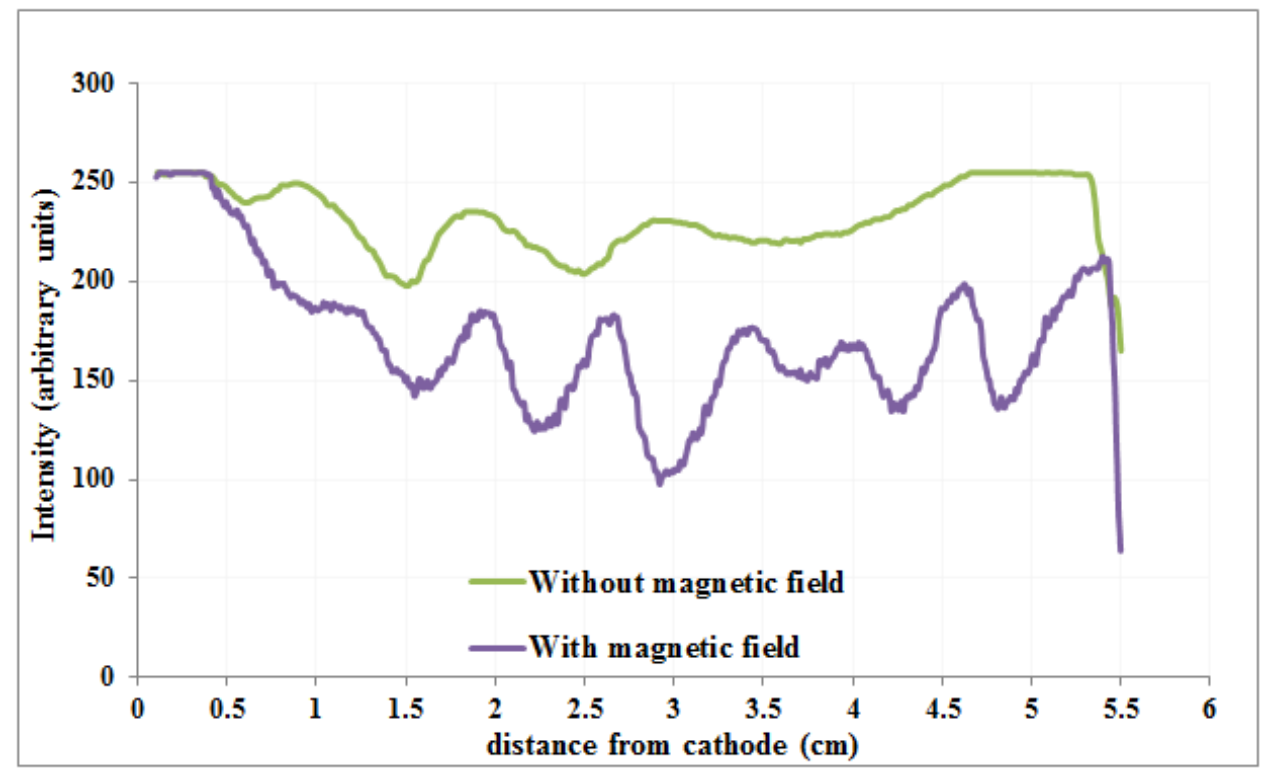

Fig. 8: Influence of magnetic field on the glow distribution between electrodes at Pressure of 0.27 mbar.

Fig. 9 shows the variation of emission intensity of plasma as a function of working pressure in two cases; with and without magnetic field. It seems that the emission intensity have a maximum value at 1.07 mbar. The magnetic field increasing the emission intensity of plasma in low pressure (less than 1 mbar). While, the presence of magnetic field causes to decreases the emission intensity of plasma for pressure greater than 1 mbar.

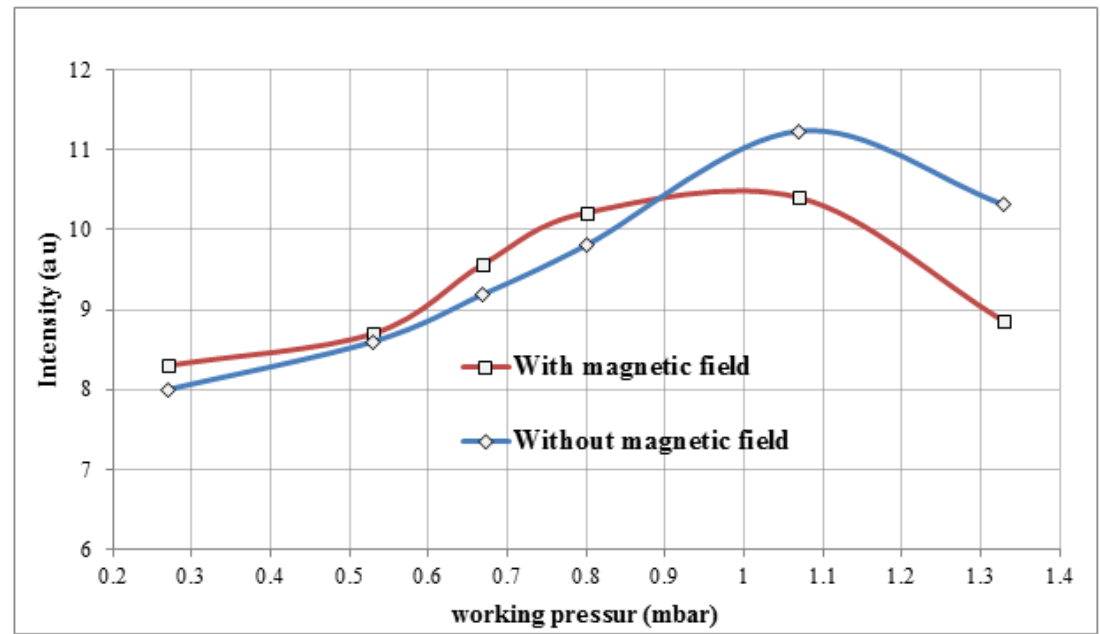

Fig. 9: Variation of emission intensity with pressure for dc discharge in Ar using different hollow cathode dimensions with and without magnetron. 


\section{Conclusions}

The spatial glow distribution in plasma produced by dc discharge in Argon gas using hollow cathode system effected by working pressure and magnetron existence. It was found that the emission intensity appear as a periodic structure and the number of intensity peaks increase with increasing the pressure and finally converted to continuous form at high pressure, especially when magnetic field existence, were the plasma be more stable with the presence of magnetic field. The emission intensity distribution have a maximum values at 1.07 mbar and decrease with more pressure.

\section{References}

[1] M. Lieberman and A. Lightenberg, 'Principles of Plasma Discharges and Material Processing' John Wiely \& Sons, INC., New York, (1994).

[2] O. Chin and C. Wong, Jurnal Fizik Malaysia, 24, 3 (2003) 107-114.
[3] D. Zhechev, V. Zhemenik, S. Tileva, G. Mishinsky, N. Pyrvanova, Nuclear Instruments and Methods in Physics Research, 204 (2003) 387-391. [4] R. Kenneth and A. Jose, Glow Discharge Plasmas in Analytical Spectroscopy. England: John Wiley \& Sons Ltd, (2003).

[5] W. Niessen and A. Davies, "A Two-Dimensional Simulation of a Hollow-Cathode Discharge, Department of Physics, University College of Swansea Singleton Park, Great Britain, (1991).

[6] P. Slevin \& W. Harrison, J. Applied Spectroscopy Reviews, (2007) 201-255.

[7] O.H. Chin and C.S. Wong, Jurnal Fizik Malaysia, 23, 4 (2002) 54-59.

[8] S. Al-Hakary, S. Muhamad, L. Dosky, International J. of Scientific \& Engineering Research, 5, 1 (2014) 1492-1499.

[9] S. Awsi, American J. of Modern Physics, 2, 6 (2013) 276-281. 